\title{
REVIEW
}

This is an open access article distributed under the terms of the Creative Commons BY-NC-ND Licence

\section{Rare earth elements in plants}

\author{
M. KOVAŘ́IKOVÁ ${ }^{1}$, I. TOMÁŠKOVÁ ${ }^{1}$, and P. SOUDEK ${ }^{2 *}$ \\ Faculty of Forestry and Wood Sciences, Czech University of Life Sciences, CZ-16521 Prague, Czech Republic ${ }^{1}$ \\ Laboratory of Plant Biotechnologies, Institute of Experimental Botany, AS CR, \\ CZ-16502 Prague, Czech Republic ${ }^{2}$
}

\begin{abstract}
Since 1960, the positive effects of rare earth elements (REE) on crop physiology have been observed, and support for photosynthesis, biomass accumulation, secondary metabolites, or enzymes has been reported in $40 \%$ of studies. A higher content of chlorophylls $a$ and $b$ as well as carotenoids have been found along with an increased efficiency of photosystem II photochemistry and electron transfer rates. An increased activity of a key photosynthetic enzyme was also found in several plants growing in soil with a higher content of REE. An appropriate amount of REE also activates the antioxidant activity of peroxidase, superoxide dismutase, and catalase. These enzymes, together with a higher content of flavonoids and carotenoids, increase the resistance of plants to oxidative stress caused by different abiotic stresses. The positive effect of REE on biomass accumulation was also confirmed, but their affection on mycorrhizal symbiosis remains ambiguous. On the other hand, an excess of REE leads to damage to plants including the chloroplast ultrastructure. Therefore, the positive and negative effects of REE remain controversial, and the mechanisms of effects of REE in plants remain poorly understood. In addition to physiological processes, the absorption, bioavailability, and translocation of REE in plants as well as their possible ecotoxicology and hyperaccumulation are discussed in this review.
\end{abstract}

Additional keywords: antioxidants, carotenoids, chlorophyll, chloroplast, ecotoxicology, hyperaccumulators, mycorrhizal symbiosis.

\section{Introduction}

Global production of rare earth elements (REE) has increased exponentially in recent decades because of their applications in wind turbines, electric motors, catalysts, solar panels, mobile phones, batteries, laptops, lasers, fiber-optics magnetic resonance tomography, new drugs, etc. World production has more than doubled in the last 20 years. Peak production occurred in 2006, with more than $137 \times 10^{6} \mathrm{~kg}$ of rare earth oxides (REO) (Walters and Lusty 2011). Over the long term, China has dominated the global REE scene, accounting for approximately 95\% of the total production (Jaireth and Hoatson 2014). Emissions from oil-fired plants, refineries, and mining practices are sources of pollution over long distances. Transport of air masses enriched with REE at a global scale has been reported since 1979. Increasing amounts of REE have been detected in several ecosystems (Tyler and
Olsson 2006). In addition to the various industries, the use of REE in agriculture has steadily increased. They are widely used as microfertilizers because lanthanides can increase crop yields. The area of fields with applied REE reached $160-290$ thousand $\mathrm{km}^{2}$ in 1995. Around 2005, REE consumption for agricultural purposes reached almost $100 \times 10^{9} \mathrm{~kg}$ per year. Moreover, REE are used as feed additives as they can improve the production of milk, eggs, and meat. However, an increased use of REE significantly increases pollution of ecosystems. In relation to this issue, the positive and negative effects of REE should be considered.

A positive effect of REE on crop production has been observed since 1960(for review see El-Ramady 2008). Appropriate amounts of REE can promote plant growth and development because they have similar physiological

Submitted 16 November 2017, last revision 16 March 2018, accepted 21 March 2018.

Abbreviations: AM -arbuscular mycorrhizis, CAT - catalase; CEC - cation exchange capacity; Chl - chlorophyll; GOT - glutamic oxaloacetic transaminase; HREE - heavy REE; LREE - light REE; POD - peroxidase; PS - photosystem; REE - rare earth elements; REO - rare earth oxides; Rubisco - ribulose-1,5-bisphosphate carboxylase/oxygenase; SOD -superoxide dismutase. Acknowledgments: This work was supported by project COST ES1407 (project No. LTC17046).

* Corresponding author; Fax: (+420) 225106 808, e-mail: soudek@ueb.cas.cz 
effects as some mineral nutrients. In this review, we summarize up-to-date information about the role of REE in plants. An increase in plant biomass by stimulating photosynthetic rate, an effect on plant resistance, and many other positive or negative effects of plants metabolism are described below.

\section{What are rare earth elements?}

Rare earth elements are trace metals that include the lanthanide group with 15 elements: lanthanum (La), cerium $(\mathrm{Ce})$, praseodymium (Pr), neodymium $(\mathrm{Nd})$, promethium $(\mathrm{Pm})$, samarium $(\mathrm{Sm})$, europium $(\mathrm{Eu})$, gadolinium (Gd), terbium ( $\mathrm{Tb}$ ), dysprosium (Dy), holmium (Ho), erbium (Er), thulium (Tm), ytterbium $(\mathrm{Yb})$, and lutetium (Lu) with an increasing atomic number (57 to 71 ) in the periodic table. According tothe International Union of Pure and Applied Chemistry (IUPAC) REE shave similar physical and chemical properties, with even being magnetic and luminescent, and are often found in the same ore deposits except unstable Pm (Hatch 2012, Jaireth et al. 2014). The lanthanides are divided into two groups (Miao et al. 2008, Long et al. 2010, Walters and Lusty 2011): the light rare earth elements (LREE) with atomic numbers from 57 to 63 ( $\mathrm{La}$ to $\mathrm{Eu}$ ), and the heavy rare earth elements (HREE) ranging from 64 to 71 ( $\mathrm{Gd}$ to $\mathrm{Lu}$ ). Despite its low atomic mass, yttrium has properties more similar to the HREE and is often included in this group (Sneller et al. 2000). Compounds containing light lanthanides are considered more soluble than compounds containing heavy ones (Sneller et al. 2000). On account of their unique and diverse chemical similarity, the REE can very easily replace one element for another in crystal structures (Walters and Lusty 2011).

These elements are natural parts of the environment. Abundances of REE in soils are influenced by texture, weather history, pedogenic processes, organic matter content, and anthropogenic activities. More than 250 minerals containing REE are known (Walters and Lusty 2011).The REE occur naturally as oxides, silicates, carbonates, phosphates, and halogen compounds(Tyler 2004a, Jaireth et al. 2014). The LREE are more common, easily extracted, incompatible, and more concentrated in the continental crust than the HREE (Walters and Lusty 2011). Most geological events cause the redistribution of REE changing the LREE/HREE ratio (Fu and Akagi 1998). Nevertheless, the occurrence of LREE is generally

\section{Factors affecting REE absorption and transport}

The uptake and transport of REE in plants have attracted attention during the last decade, but the available information on the soil-plant system enriched with REE is limited and fragmented (Wahid et al. 2003, Hu et al. 2004). With changing environmental conditions, understanding the biological impact of REE especially on natural plants is required. Nevertheless, the uptake, bioavailability, and translocation of REE within root systems are overlapping with the uptake and translocation higher than HREE as it follows the Oddo-Harkins rule. According to this rule, elements with even atomic numbers are more abundant than their neighbours with odd atomic numbers because of their greater relative stability of atomic nuclei (Jaireth et al. 2014). In the earth crust, the content of REE in soils in mining areas or mine tailings also obey the Oddo-Harkins rule (Snelleret al. 2000, Miao et al. 2011, Walters and Lusty 2011, Aide and Aide 2012, Anawar et al. 2012, Gonzalez et al. 2014, Jaireth et al. 2014).

The term "rare" does not refer to the relative crustal abundance of these elements (Walters and Lusty 2011) but to the absence of concentrated REE in a pure ore deposit as other elements (e.g., gold) (Gonzalez et al. 2014). The total content of REE increases from 11 to 12 $\mathrm{mg} \mathrm{kg}^{-1}$ in the lower crust up to $\sim 170 \mathrm{mg} \mathrm{kg}^{-1}$ in the upper crust. Rare earth elements are concentrated in the earth's crust in substantial quantities, but they are widely dispersed and present in smaller quantities near the earth's surface (Dobransky 2013). The total content of $\mathrm{REE}$ ranges from 54 to $130 \mathrm{mg} \mathrm{kg}-1$ in the following order: $\mathrm{Ce}>\mathrm{La}=\mathrm{Y}>\mathrm{Sc}>\mathrm{Nd}>\mathrm{Sm}>\mathrm{Pr}>\mathrm{Gd}>\mathrm{Dy}>\mathrm{Eu}$ $>\mathrm{Tb}>\mathrm{Er}>\mathrm{Yb}>\mathrm{Ho}>\mathrm{Lu}>\mathrm{Tm}$ (Redling 2006). Since they have similar chemical and physical characteristics, the lanthanide elements and yttrium often occur together in nature and can be mined only together as co-products. Therefore, the recoverable amount of individual REO depends on the deposit composition (Polinares 2012).

The chemical nature of REE is a function of their atomic number (Merten et al. 2004). The most common valence for lanthanides is +3 when they are dissolved although some of them can be present in +2 and +4 oxidation states (Walters and Lusty 2011, Gonzalez et al. 2014). The Ce-anomaly is reported under oxidizing conditions, and typically trivalent ions $\mathrm{Ce}^{3+}$ are transformed to $\mathrm{Ce}^{4+}(>300 \mathrm{mV}$ at $\mathrm{pH} 7)$. The Eu-anomaly usually occurs under reducing conditions; $\mathrm{Eu}^{3+}$ is reduced to $\mathrm{Eu}^{2+}(<-350 \mathrm{mV}$ at $\mathrm{pH} 7)$.

of other mineral nutrients.

Firstly, the adsorption and desorption of REE are affected by the physico-chemical properties of the soil (Wahid et al. 2003, Liang et al. 2005, Loell and Albrecht 2011, Miao et al. 2011, De Araújo et al. 2012): 1) Uptake of REE via roots is linked to Fe-oxyhydroxides in the rhizosphere (Brioschi et al. 2013, Durães et al. 2014); 2) The mobility of elements within the soil profile depends on the $\mathrm{pH}$ value of the rhizosphere and the redox 
potential of the soil (Cao et al. 2001, Wu et al. 2001, Shan et al. 2002, Tyler 2004b, Durães et al. 2014); 3) Uptake of REE by plants tends to be higher at a low pH (Cao et al. 2001, Shan et al. 2002, Tyler 2004a); 4) Biochemical cycling and fractionation of REE in soil resulting from atmospheric deposition (Stille et al. 2009); 5) The cation exchange capacity (CEC) of soil is an important factor affecting the adsorption and desorption of (not only) REE (Jones 1997, Shan et al. 2002, Shan et al. 2003b); 6) The plant uptake rate is dependent on the valence of an element (Tyler 2004b); 7) The Casparian stripes in plant root endodermis limit uptake of REE (Hu et al. 2004, Brioschi et al. 2013); 8) Complexes formed by low-molecular-mass-organic acids and other plant root exudates predict the bioavailability of REE (Fu et al. 2001, Zhimang et al. 2001, Shan et al. 2002, 2003a,b); 9) Organic and inorganic ligands play an important role in REE absorption by plant roots and fractionation of REE (Fu et al. 1998, 2001, Zhimang et al. 2001, Shan et al. 2003b, Ding et al. 2005, 2007, Liang et al. 2005, Ma et al. 2008, Zanin and Zamirailova 2009, Durães et al. 2014); 10) The addition of fulvic, humic, malic, and citric acids, histidine, or ethylene diamine tetraacetic acid (EDTA) changes bioaccumulation of REE in plants as metals complexed with, e.g., fulvic acids, are more available to plant roots (Zhimang et al. 2001, Shan et al. 2003a, Ding et al. 2005, Liang et al. 2008); 11) The affinity of plasma membrane affects absorption of individual elements $(\mathrm{Hu}$ etal. 2004); 12) Chelators (aspartic acid, asparagine) may have a positive effect on uptake of REE (Wu et al. 2013); 13) Uptake of REE may be facilitated by an increased nitrogen and potassium fertilization and decreased by addition of phosphates (Hu et al. 2004).

Roots preferentially absorb LREE below $50 \mathrm{~cm}$ soil depths (Stille et al. 2009, Brioschi et al. 2013, Durães et al. 2014). The bioavailability of compounds to plants represents one of the most important issues for environmental studies. Studies have indicated the importance of speciation and complexing REE with various ligands under different $\mathrm{pH}$. Rare earth elements complexation with carbonate ions predominates in the majority of natural waters of moderate to high $\mathrm{pH}$ where carbonates are the major component (Johannesson and Lyons 1995). Speciation calculations showed that REEcarbonate complexes dominate and typically account for more than $99 \%$ of each rare earth element in solution. In almost neutral $\mathrm{pH}(7 \leq \mathrm{pH} \leq 9)$, the inorganic speciation of the $\mathrm{REE}$ in complexes with carbonate includes $\mathrm{LnHCO}_{3}{ }^{2+}, \mathrm{LnCO}_{3}{ }^{+}$, and $\mathrm{Ln}\left(\mathrm{CO}_{3}\right)_{2}^{-}$, and that with phosphate $\mathrm{LnH}_{2} \mathrm{PO}_{4}{ }^{2+}, \mathrm{LnHPO}_{4}{ }^{+}, \quad \mathrm{Ln}\left(\mathrm{HPO}_{4}\right)^{2-}$, and $\mathrm{LnPO}_{4}$. In water with a low $\mathrm{pH}(\mathrm{pH}<6.5)$, free metal ions dominate the speciation of REE (Johannesson et al. 1996).

Other extremely important soil variables that influence bioavailability include redox potential, soil texture, and organic matter content (Cao et al. 2001). Interactions among elements and compounds influence availability via antagonistic or synergistic mechanisms as chemically similar elements may compete for the same binding sites (e.g., $\mathrm{Ca}$ and REE) (Thomas et al. 2014). Rare earth elements release increases with the decrease of $\mathrm{pH}$, solubility is comparable under the same redox potential, but REE release is enhanced when redox potential decreases within the same $\mathrm{pH}$ values. It seems that the mobilities of $\mathrm{La}, \mathrm{Gd}$, and Y depend mainly upon $\mathrm{pH}$ value, whereas the release of $\mathrm{Ce}$ depends both upon $\mathrm{pH}$ and upon redox potential. Rare earth elements release is positively correlated with the release of $\mathrm{Fe}$ and $\mathrm{Mn}$ (Cao et al. 2001). Adsorption capacities of REE are significantly correlated with CEC of soils. The CEC is probably also related to humic acid content as Gu et al. (2001) found a significant linear relationship between humic acid and CEC. Generally, CEC, redox potential, mobility, and subsequent availability of rare earth element cations in the soil increase at a lower $\mathrm{pH}$ (Shan et al. 2002, Thomas et al. 2014).

Rare earth elements uptake by plants is not only controlled by the plant itself but depends on their content in soil, soil water pool, and other minerals (Weltje et al. 2002, Brioschi et al. 2013). Water-soluble and exchangeable fractions of REE are the most available ( $\mathrm{Li}$ et al. 1998, Cao et al. 2000, Xu and Wang 2001, Zhang and Shan 2001, Redling 2006). Other sources include silicate particles in soil (Fu et al. 2000, Fu et al. 2001) and airborne particles (averaging less than $2.5 \mu \mathrm{m}$ ) or gasses absorbed by vegetation (Sun and Zhao 1994, Peresedov and Gundorina 1997).

There are two different options for REE distribution patterns in an ecosystem: a distribution pattern in plants and a distribution pattern in soil. The amount of REE in plants is not correlated with the content of REE in the rhizosphere (Wyttenbach et al. 1998, De Araújo et al. 2012, Durães et al. 2014)either due to a greater control of REE uptake by plant properties (Tyler and Olsson 2005). Nevertheless, a significant linear correlation between soil REE content and corresponding leaf or root REE content in palms growing in a sandy soil has been observed (Wahid et al. 2003). and also similarities in distribution patterns of REE between soil and seeds were observed (Wyttenbach et al. 1994, Liang et al. 2005). Nevertheless the process of REE transportation and accumulation by plants is influenced by different REE biogeochemical characteristics, e.g., of goldfields. Pinus massoniana grown in the gold mineralization zone transports REE to the aboveground parts more efficiently comparing to the background areas. (Miao et al. 2011). By contrast, higher amounts of REE ( 3 to 7 times higher) are consistently found in the rhizosphere than in trees (oak, spruce, and beech) (Brioschi et al. 2013) and natural plant vegetation samples (Durães et al. 2014). There are huge differences in REE content in herbaceous plants but with no clear relationship between REE in leaves and REE soil content

Light rare earth elements are more mobile and preferentially exported by surface and subsurface runoff, which also implies that LREE are more available for root absorption than HREE (Ozaki et al. 2000, Hagerberg and Thelin 2003, Brioschi et al. 2013). This enrichment is 
probably related to a higher mobility of LREE in the soils mentioned above and amplified by a higher stability of dissolved HREE complexes in soil water. Roots preferentially absorb free ions rather than dissolved complexes (Brioschi et al. 2013). The actual fractionation of REE reflects a tendency toward a decreasing transfer of REE with increasing atomic mass and decreasing ionic radius (Tyler and Olsson 2005). Uptake of non-essential ions, their retention in roots, and redistribution into specific organs are species-specific and depend on the metal resistance mechanisms of the species (Närhi et al. 2014) and properties of the endodermis. Moreover, REE are potentially associated with different development stages (Brioschi et al. 2013, Durães et al. 2014). A positive correlation between LREE amounts and Fe-oxyhydroxides in bedrock and soil was found. Content of REE in tree roots can correlate with Fe-Mnoxyhydroxides content in the limestone soils with Fe-oxyhydroxides in the clay-humus soil. Plants seem to use the same mechanisms applied for the micronutrient Fe to absorb REE (Brioschi et al. 2013).

A strong relationship between plants and silicon seems quite natural due to its substitution in the soil. Moreover, REE and Si are concentrated in silicate rock, and oxides of REE are very stable as lithophilic elements. There is a linear accumulation of REE as well as $\mathrm{Si}$ in Norway spruce (Picea abies) (Wyttenbachet al. 1994). By contrast, a strict relationship between them even within the same tissue of different species or within tissues from a single species has not been found in other tree species (Fu et al. 2001).

Bioaccumulation and plant hyperaccumulators: Plants take up a wide range of mineral nutrients including REE. Some plantspecies are able to accumulate metal and metalloid trace elements in their biomass in considerably higher amounts in comparison to other species; e.g., Sebertiaacuminata from New Caledonia contains $25 \%$ of nickel in dry latex. A high accumulation of metals within plant tissue without a strong negative impact on growth, development, or reproduction is called hyperaccumulation. Understanding uptake, transfer, and storage of metals in hyperaccumulators lies at the interface between geochemistry and plant physiology(Wang et al. 2003). Moreover, hyperaccumulators as well as common plants can solubilize REE in soil (Shan et al. 2003a,b). Accumulation of lanthanides seems to be a characteristic of Pteridophyta(De Araújoet al. 2012). Typical examples of REE hyperccumulators are Dicropteris dichotoma and Pronephrium simplex. The contentof LREE in dry mass of leaves of $D$. dichotoma is approximately $0.7 \%$ (Shan et al. 2003a), and $P$. simplex accumulates REE in lamina up to $1.2 \mathrm{mg} \mathrm{g}^{-1}$ (d.m.) with a higher affinity to LREE (Lai et al. 2006). Also fern Alsophila sternbergii is mentioned among species with a high ability to accumulate LREE (De Araújo et al. 2012). Concentration ratio defined as the quotient of plant tissue/substrate) elemental concentration (Wahid et al. 2003), or transfer factor $\left(\mathrm{TF}=\mathrm{Cplant} / \mathrm{C}_{\text {soil }}\right)$ can be used to describe the ability of plants to accumulate REE in the plant biomass. Pachystroma longifolium (França et al. 2002), Sphagnum sp. (Markert and De Li 1991) and even citrus can be considered as bioaccumulators. The leaf/soil ratio of $\mathrm{La}$ (0.62-1.09) makes citrus even a stronger bioaccumulator than the two aforementioned plants (Turra et al. 2013). As described above, a larger pool of total REE in soil is usually reflected in higher amounts of REE in plant tissue, up to, e.g., $9880 \mathrm{ng} \mathrm{g}^{-1}$ (d.m.) in Populus sieboldii (Fu et al. 2001) and $10.1 \mathrm{nmol} \mathrm{g}^{-1}(\mathrm{~d} . \mathrm{m}$.) in Anemone nemorosa (Tyler and Olsson 2005). Three species (Carlina corymbosa, Erica australis, and Lavandula luisierra) growing on mine tailings can accumulate high amounts of REE [La 0.45 - 0.57, Ce 0.68 - 2.41 $\mathrm{mg} \mathrm{kg}^{-1}$ (d.m.)] (Anawar et al. 2012).

Aspartic acid and asparagine promote the remediation capabilities of the hyperaccumulator Phytolacca americana when used as a chelator (Wu et al. 2013). In Lycopersicon esculentum, application of aspartic acid and asparagine enhances $\mathrm{La}$ absorption into roots, whereas application of glutamic acid and histidine affects La translocation from roots to shoots (Wu et al. 2013). These findings have important implications for the phytoremediation of REE contamination in soil.

The importance of mycorrhizal fungi: Mycorrhizis acts as one of the most important factors influencing the availability of REE to plants. Root exudates with fungal hyphae and roots promote mineral acquisition and dissolution in the rhizosphere (Tyler and Olsson 2005). Acid and chelating compounds are released into the soil to dissolve phosphate minerals, silicate particles, and others sources of REE (Fu et al. 2001).

Endomycorrhizal fungi, especially arbuscular mycorrhizal (AM) fungi can improve biotic and abiotic stress tolerance of its host plant. They enable uptake of mineral nutrients including REE, but they can also act as a barrier to REE. The content of REE in sporocarpsis similar or higher than in host plants in dependence of soil properties(Aruguete etal. 1998). In ectomycorrhizal fungus, calcium ions can be substituted by lanthanide ions (Aruguete et al. 1998).

An increasing La accumulation in Astragalus sinicus is associated with an increasing content of $\mathrm{La}$ in soil regardless of mycorrhizal or non-mycorrhizal treatment. In comparison to other plants, in maize and sorghum, AM colonization significantly reduces La content in shoots and roots (Guo et al. 2013). Application of higher La doses [5 mg kg-1(soil)] decreases activity of succinate dehydrogenase (SDH) and alkaline phosphatase (ALP) in fungal mycelium. These two enzymes are considered as an indicator of AM fungi colonization (Chen and Zhao 2007)

Treatment with AM fungi significantly increases $\mathrm{N}, \mathrm{P}$, and $\mathrm{K}$ content in shoots and roots of Astragalus sinicus and growth of Zea mays and Sorghum bicolor in soil enriched with REE. Dry masses of the investigated plants increase by 211 to $387 \%$ in shoots and roots compared with the non-inoculated treatment (Chen and Zhao 2009, 
Guo et al. 2013). An AM fungus colonization might be effective for mitigation of La toxicity by significantly improving $\mathrm{P}$ content in shoots and roots and therefore the amount of plant biomass (Chen and Zhao 2007).

Rare earth elements content in plants affect inoculation of fungi on roots. Seedlings of Pinus sylvestris accumulate REE in roots $16-23$ times more than in shoots, but this process is dependent on the inoculated fungi (Hagerberg et al. 2003, Chen and Zhao 2007). The effect of mycorrhizal fungi colonization on plant REE uptake probably depends on plant species, substrate, species of fungi, and concentration of REE.

Heavy metal toxicity to plants is strongly affected by the amount of REE in soil due to their synergic effects. However, amelioration of heavy metal toxicity is possible by a low concentration of REE. A significant decrease in content of certain heavy metals in shoots and roots has been observed in Zea mays and Sorghum bicolor inoculated with AM fungi. Glomalin produced by AM fungi can decrease metal toxicity by reducing metal absorption and enhancing plant tolerance (Hildebrandt and Regvar 2007, Guo et al. 2013).

Absorption and transport within a root system: Low molecular mass organic acids are important root exudates; they can be produced as a consequence of plant protein decomposition (Shan et al. 2002). Due to their metal-chelating and/or complexing properties, they can influence metal solubility in soils and uptake by plants (Shan et al. 2002, 2003a,b). However, adsorption and desorption of REE from soil are closely related to the stability of complexes formed between REE and root exudates. Nevertheless, for citric, malic, and tartaric acids, adsorption of REE decreases to varying extent in comparison to nitrates and acetic acid. The suppression of REE adsorption follows the order citric acid $>$ malic acid $>$ tartaric acid $>$ acetic acid consistently with the order of stability of the complexes of REE with these organic acids (Shan et al. 2002).

Organic acids, redox potential, and soil $\mathrm{pH}$ are important factors affecting REE bioavailability (Shan et al. 2002, 2003b). Although the relationship between REE desorption and soil $\mathrm{pH}$ is complicated and depends, e.g., on soil acid type, desorption of REEs decreased with increasing equilibrium solution $\mathrm{pH}$ (Shan et al. 2002). Organic acids (citric and malic acids) and histidine alter accumulation of REE in plants depending on the soil type (Shan et al. 2002, 2003a). Increasing content of organic acids increase desorption of REE (Shan et al. 2002). Nevertheless, the promotion of REE uptake from soil with a low pHcan be observed. Histidine and organic acids promote uptake and sequestration of LREE in Dicropteris dichotoma leaves (Shan et al. 2003a). Low concentrations of fulvic acid (FA) in wheat increases bioaccumulation of REE in different parts of the plant. Adding increasing or high concentrations of FA (Zhimang et al. 2001), EDTA (Ding et al. 2007), and citrate changes glutamic oxaloacetic transaminase (GOT) activity and so decrease bioaccumulation of REE (Zhimang et al. 2001). Different changes in LREE and HREE content in leaves is observed with increasing content of EDTA and $\mathrm{Ca}^{2+}$ (Ding et al. 2007).

In addition, physicochemical properties of soil, such as organic matter, iron, manganese, and aluminum oxides, affect the bioavailability of REE to plants. The absorption capacity of REE is even significantly correlated with the cation exchange capacity of soil(Shan et al. 2002).

Glutamic oxaloacetic transaminase and tetrad effect: Variations in GOT activity provide important information on the REE bioavailability and accumulation in the plant body. In plants, GOT activates nitrogen and amino acid metabolism. A correlation between bioaccumulation of REE in roots and shoots and GOT activity has been demonstrated in Dicranopteris dichotoma and Triticum aestivum (Zhimanget al. 2001, Wang et al. 2003).

A valuable indicator of the distribution pattern of REE among organs or tissues in the plant body seems to be the tetrad effect or concentration ratio(Wahid et al. 2003). The tetrad effect can cause partitioning chondritenormalized REE patterns, where chondrite normalized means ratio of $\mathrm{La}_{2} \mathrm{O}_{3}$ and $\mathrm{La}$. The ratios of samples and chondrite are plotted on a logarithmic scale against the atomic number into four segments called tetrads (the first tetrad, La-Ce-Pr-Nd and the fourth tetrad, Er-Tm-Yb-Lu). The tetrads form $\mathrm{W}$ or $\mathrm{M}$ shape after connection of all REE normalized concentration in the graph (Masuda et al. 1987). The tetrad effect has been described for dicotyledons, monocotyledons, gymnosperms (Fu et al. 2001, Ding et al. 2005, Ding et al. 2007, Durães et al. 2014), and ferns (Fu et al. 1998), and the REE tetrads shape in different plant organs can provide useful information about REE transportation in the environment (Masuda et al. 1987, Ding etal. 2005, 2007).

In nature, citrate plays a very important role in altering REE bioavailability by complexation with REE in soil (Ding et al. 2005). The amount of ligand affects REE patterns in different parts of a plant (Fu et al. 2001).

A higher affinity between REE and inorganic ligands, such as phosphate $\left(\mathrm{PO}_{4}{ }^{3-}\right)$, plays important roles in REE bioaccumulation (Ding et al. 2005, Liang et al. 2008). Generally, the amount of REE in leaves decreases with increasing amount of applied phosphate, but no changes in REE occur in wheat roots (Ding et al. 2005). A similar result is achieved in soybean: Next to the Pi (as an anorganic ligand) REE fractionation is influenced by cell wall absorption (Ding etal. 2007). 


\section{Distribution of REE in plants}

Location of REE in the intra- and extra-cellular space: Understanding the REE localization in plant tissues is very important ( $\mathrm{Hu}$ et al. 2004). The largest amount of REE (68\%) is presented as REE-pectin complexes in cell walls (Lai et al. 2006). A large amount of $\mathrm{Ca}^{2+}$ is stored in the cell wall as calcium pectinate. Nevertheless, carboxyl groups of pectin acid which have not been esterified provide many binding sites for metal ions (Lai et al. 2006). The lanthanides are able to substitute for $\mathrm{Ca}^{2+}$-as they are approximately of the same size as $\mathrm{Ca}^{2+}$. Moreover, their trivalency gives them a much higher charge to volume ratio so that they usually have much higher affinities than $\mathrm{Ca}^{2+}$ for the given binding sites (Evans 1983). Due to the chemical properties of lanthanides the plant physiology could be changed by $\mathrm{Ca}^{2+}$ regulation on the cellular level (Zeng et al. 2000, Tyler and Olsson 2005, Durães et al. 2014).

A high affinity of $\mathrm{La}^{3+}$ to the cell wall might be one possible reason for its increased uptake by ferns. Addition of $\mathrm{Ca}^{2+}$ and especially of $\mathrm{La}^{3+}$ accelerates growth of Dryopteris erythrosora. Rare earth elements are absorbed to a higher degree in comparison with other non-essential elements. The $\mathrm{La}^{3+}$ and $\mathrm{Eu}^{3+}$ can be absorbed by plant cells and bind to the membranes of chloroplasts, mitochondria, cytoplasm, and nucleus (Gao et al. 2003). Since the ratio of charge to the ionic radius of REE is higher than that of $\mathrm{Ca}^{2+}$, REE may have a higher ability to bind to pectic acid in the chloroplast of Pronephrium simplex. Rare earth elements are distributed almost equally in the chloroplast membrane and thylakoids, and most REE in the thylakoids are bound to photosystem (PS) II complex (Lai et al. 2006). Thus, it is also possible that REE can replace $\mathrm{Ca}^{2+}$ and bind to PS II protein (Wang et al. 2003).

Apoplastic and symplastic pathways, xylem sap: Light rare earth elements accumulate in the cell wall, intercellular space, plasmalemma, vesicles and vacuoles of root endodermis and stele cells but not in the Casparian strips (Shan et al. 2003a). Apoplastic and symplastic pathway mechanisms of REE transport have been identified (Shan et al. 2003a). Along the apoplastic pathway, REE are passively transported through the cell wall according to a concentration gradient and do not cross the plasma membrane. In the symplastic pathway, solutes are transported across the plasmalemma. Both the apoplastic pathway and the symplastic pathway are interrupted by the endodermis with the Casparian strips(Lehmann et al. 2000, Shan et al. 2003a). A ionselective cell wall located in the endodermis modifies or blocks transfer of specific ions. A huge difference in REE content between roots and other parts of a plant body is just caused by the endodermis. In some special roots, such as the nodal roots of Hordeum vulgare, the role of endodermis largely performs the exodermis (Lehmann et al. 2000). Deposits of LREE are observed in the phloem and xylem of the rhizomes (Shan et al. 2003a,
Brioschi et al. 2013). Nevertheless, the majority of REE $(97 \%)$ in the xylem sap of soybean are combined with certain ligands (Ding et al. 2007).

The LREE and HREE layout varies according to the type of plants, but there is usually a slight enrichment of HREE in roots, confirming the reduced ability of plants to translocate HREE (Ding et al. 2007). Stems and leaves are enriched with LREE (Brioschi et al. 2013, Durães etal. 2014). The leaf position and its area differ in transpiration stream bulk which in return influences the fractionation between HREE and LREE within a plant The HREE are preferentially transported with transpiration stream, leading to corresponding changes among different stem segments (Ding et al. 2007).

Cerium and europium anomaly: The anomaly described in several species is based on their lower or higher content in soil solution in comparison to other REE due different oxidation states (described above). Variations of different redox potential or the $\mathrm{pH}$ of soils can influence adsorption mechanisms. Generally, the REE pattern are comparable between plant organs and rhizosphere. Ce dominates in leaves and roots but it is depleted in stems relative to other REE (Fu et al. 1998, Brioschi et al. 2013, Durães etal. 2014). Cerium has a negative anomaly with respect to soil in Picea abies, Abies alba, Acer pseudoplatanus, Hedera helix, Rubus fruticosus, Dryopteris filix-mas, Taxodium japonicum, Populus sieboldii, Sasa nipponica, Tea sinensis, and Vicia villosa (Wyttenbach et al. 1998, Fu et al. 2001). The conditions leading to the Ce anomaly are not uniform as demonstrated by the different sizes of the anomaly in the various species and by its variation between individuals of one species. Small changes in the redox potential of the rhizosphere might contribute to this variability (Wyttenbach et al. 1998). Sap samples are additionally characterized by positive $\mathrm{Ce}$ anomalies, suggesting that REE may be associated with colloidal Fe-oxyhydroxide particles (Brioschi et al. 2013).

The $\mathrm{Eu}$ anomaly is dependent on the soil type. Limestone soils show strong positive $\mathrm{Eu}$ anomalies. A slight positive $\mathrm{Eu}$ anomaly occurs in granite soils, whereas no significant anomalies are found in carbonatite soil (Brioschi et al. 2013). The Eu anomaly is greater in roots and leaves than in stems, probably because of participation in metabolic functions due to similarity with calcium in membrane channels. The Eu anomaly is also well described in some crops, especially in stems and grains (Ding et al. 2006).

Fractionation of REE within plants: The REE content pattern called the fractionation is soil $>$ roots $>$ leaves (needles) $>$ stems (trunks) $>$ grains (seeds) in trees (spruce, beech, oak, and pine) and fern (Matteuccia) under natural conditions, and in wheat, rice, and vegetables after application of a REE fertilizer (Sun et al. 1994, Fu et al. 1998, Wen et al. 2001, Miao et al. 2011, 
Brioschi et al. 2013). A hyperaccumulator Dicropteris dichotoma follows the pattern leaves $>$ roots $>$ stems (Miao et al. 2011). The content of REE in plants was found higher in a mining area than in a non-mining area (Wang et al. 2006, Nazreen et al. 2017). Other results indicate that the total REE content in roots and stems is lower than in leaves because translocation of REE occurs in roots and stems (Miao et al. 2011). However, REE in Populus sieboldii follow the pattern leaves $>$ main roots $>$ trunks (Fu et al. 2001), and in Citrus sinensis budded on C. limonia, the pattern soil $>$ leaves $>$ peel $>$ pulp $>$ seeds $>$ juice (Turra et al. 2013).

Different REE patterns may reflect a different mobility of REE in plants (Fu et al. 2001, Khan et al. 2017, Mikolajczak et al. 2017), but there is no clear correlation between increasing or decreasing accumulation and atomic number (Gonzalez etal. 2014).

\section{Impact of REE on plant anatomy and physiology}

Leaf anatomy, stomatal conductance, and transpiration rate: Reports on these topics are very rare. Rare earth elements are clustered in the cell wall, cytoplasm, and chloroplasts in leaf epidermal and mesophyll cells (Wang et al. 2006). The effect of yttrium has been described in young maize plants, but a synergic effect with other REE is missing. The presence of $\mathrm{Y}$ $(10 \mathrm{mM})$ reduced maize growth and the length and width of stomata. Those changes are more pronounced on the abaxial than adaxial epidermis and contribute to prevention of water loss. The total leaf area declines, which might explain an increase in stomata density. Transpiration rate, stomatal conductance of water vapor, and water content also decrease (Maksimović et al. 2014). Stomatal conductance and leaf water potential of maize seedlings consistently decline with an increasing $\mathrm{Y}$ dosage from 0.05 to $0.5 \mathrm{mg} \mathrm{g}^{-1}$ (dry soil). Moreover, an appropriate dosage of $\mathrm{Y}$ of $0.05 \mathrm{mg} \mathrm{g}^{-1}$ (dry soil) improved water use efficiency (Maksimović et al. 2014).

Photosynthesis: There are only a few reports concerning the effects of REE on photosynthesis. The $\mathrm{Ce}^{3+}, \mathrm{Nd}^{3+}$, and $\mathrm{La}^{3+}$ promote growth and increase the $\mathrm{Chl}$ content and photosynthetic rate (Hong et al. 2002, Fashui and Xuefeng 2003, Hong et al. 2005). Treatments with $\mathrm{Ce}^{3+}$ increase fresh and dry masses, photosynthetic rate, and synthesis of Chl in Spinacia oleracea (Fashui and Xuefeng 2003, Hong et al. 2005). Further, REE can promote photosynthesis and crop yield by regulating ribulose-1,5-bisphosphate carboxylase/oxygenase (Rubisco) activity (Chen et al. 2000, Hong et al. 2005, Liu et al. 2007) and by improving light energy transfer from PS I to PS II (Liu et al. 2007). In the Chl molecule, $\mathrm{La}^{3+}$ may substitute for $\mathrm{Mg}^{2+}$ when there is lack or absence of $\mathrm{Mg}^{2+}$ in solution (Evans 1983, Hong et al. 2002). Deposits of REE are found in chloroplasts of intact mesophyll cells, mainly in thylakoid grana of Dicranopteris dichotoma and Spinacia oleracea (Shan et al. 2003a, Lai et al. 2006,
Nevertheless, Tyler and Olsson (2006) published the presumption that uptake from atmospheric deposition is positively related to a high ionic charge and atomic mass. There is some deflection in the absolute amount of elements during a growing season in leaves of Fagus sylvatica depending on their ionic charge. The amounts of $\mathrm{REE}$ in leaves of beech increase during early summer, stay almost the same during middle summer to autumn, and increased strongly in winter by direct passive uptake from atmospheric deposition (Tyler and Olsson 2006). The content of elements in soil and plant tissues decreases in the order $\mathrm{Ce}>\mathrm{La}>\mathrm{Nd}>\mathrm{Pr}>\mathrm{Gd}>\mathrm{Sm}$ (Emmanuel et al. 2010a,b, Wahid et al. 2003) with the exception of La being slightly more abundant than $\mathrm{Ce}$ in leaves (Wahid et al. 2003). Other authors reported the order $\mathrm{Ce}>\mathrm{La}>\mathrm{Pr}>\mathrm{Nd}$ in fern (Shan et al. 2003a).

Wang et al. 2006). Next to the chloroplasts, the REE were deposit in the cell walls and vacuoles. Comparison of plants from mining and non-mining areas has shown that the content of Chl $a+b$ and $\beta$-carotene is greater in plants from mining areas, but the $\mathrm{Chl} a / b$ ratio is similar. The reason of higher content of $\beta$-carotene may be associated with the demand for extra energy quenching when the chloroplast membrane is damaged. Due to the higher amount of photosynthetic pigments the efficiency of PS II photochemistry and electron transport rate are significantly enhanced in the plant leaves from mining areas (Wang et al. 2006).

One of the main limiting factors of photosynthetic rate is the amount and activity of the Rubisco. In Nicotiana tabacum, $\mathrm{La}^{3+}$ at low concentrations significantly promotes Rubisco activity in vivo, and lanthanides in the order $\mathrm{Ce}^{3+}>\mathrm{La}^{3+}>\mathrm{Gd}^{3+}\left(\mathrm{Ln}^{3+}\right)$ increase the activity of Rubisco in vitro (Chen et al. 2000). There is a presumption that $\mathrm{Ln}^{3+}$ can replace $\mathrm{Mg}^{2+}$ to form the active site of Rubisco during the activation process. In the Rubisco-La complex, La is bound to the oxygen atoms of amino acid residues (Chen et al. 2000). Experiments with spinach revealed that $\mathrm{La}^{3+}$ and $\mathrm{Ce}^{3+}$ treatments significantly accelerate the photosynthesis. The dry mass was also enhanced thus $\mathrm{La}^{3+}$ and $\mathrm{Ce}^{3+}$ treatments promote accumulation of organic substances (Hong et al. 2005). The mechanism by which REE increase the production of plant biomass is the promotion of photosynthetic carbon fixation by increased Rubisco activity. Rare earth elements also induce expressions of nuclear and chloroplast genes. Nevertheless, each individual element from REE can form a different complex with Rubisco, mainly the secondary structure of this complex is different (Hong et al. 2005).

Nearly a half of the total amount of REE in chloroplasts is associated with PS II in fern thylakoids, whereas only $6.4 \%$ of REE is found in the PS I fraction (Lai et al. 2006). Therefore, REE are randomly integrated 
with $\mathrm{Chl}$ and mainly localized in the protein structure of the PS II system (Wang et al. 2003, Lai et al. 2006). In chloroplasts the REE are probably bind to the carboxyl and hydroxyl oxygen of glutamic or asparagic acid. (Wang et al. 2003). The $\mathrm{La}^{3+}$ significantly improves PS II formation and enhances electron transport rate. Moreover, appropriate amounts of $\mathrm{Ce}^{3+}$ positively affects absorption of light energy, its transformation, electron transport rate, and photophosphorylation (Fashui and Xuefeng 2003, Yang et al. 2005, Zhou et al. 2009).

The increase of photosynthetic rate of spinach by $\mathrm{Ce}^{3+}$ might be related to the changes in PS II as well as to the electron transport rate (Fashui and Xuefeng 2003). Promoting activity of PS II and oxygen evolving rate by $\mathrm{Ce}^{3+}$ is mentioned also by Liu et al. 2007.

In addition, $\mathrm{Ce}^{3+}$ treatment can improve light absorption and the excitation energy distribution in both photosystems in case of $\mathrm{Pb}^{2+}$ pollution. The $\mathrm{Ce}^{3+}$ treatment together with $\mathrm{Pb}^{2+}$ pollution can maintain the stability of the chloroplast membrane and improve photosynthesis (Zhou et al. 2009), even accelerate oxygen production (Liu et al. 2007). Further, $\mathrm{Ce}^{3+}$ treatment can protect chloroplasts from aging during long-term photooxidation in Spinacia oleracea as it can significantly decrease accumulation of reactive oxygen species. Moreover, it reduces the content of malondialdehyde and maintains stability of the membrane structure (Yang et al. 2005).

Secondary metabolism: Under natural conditions, plants are exposed to abiotic and biotic factors to stimulate production of secondary metabolites. Rare earth elements may act as elicitors to increase secondary metabolite synthesis (Wu and Wang 2001). Antioxidants can protect plants against reactive oxygen species, which accumulate during stresses. The antioxidants include, e.g., superoxide dismutase (SOD), catalase (CAT), ascorbate peroxidase, ascorbate, and glutathione. The enzymes CAT, peroxidase (POD), and phenylalanine ammonia lyase are activated by REE at low concentrations $(0-200 \mu \mathrm{M})$, but when the concentration of REE exceeds $300 \mu \mathrm{M}$, the

\section{Growth and yield of crops and tree species}

Negative, positive, or no effects of REE on plant growth, and crop and tree yields have been observed in many countries around the world since 1933 (Hu et al. 2004). Application of REE in a form of foliar spray, additions of solid or liquid fertilizers, and seed treatments were used in more than 100 species (Hu et al. 2004, Redling 2006).

Low concentrations of REE stimulate growth, whereas high doses of REE inhibit growth (Zeng et al. 2006,, Emmanuel et al. 2010a,b, Zhang et al. 2013). The REE application can have a beneficial effect by improving the growth and development of plants when supplied in an appropriate concentration (Xu and Wang 2007, Zhang et al. 2013). However, an excess of REE can cause toxicity (Gonzalez et al. 2014), which depends on enzyme activities decrease significantly. Expressions of some POD isozymes are inhibited, however, some other new POD isozymes are induced by REE. Another study suggested that REE increase POD and SOD activities as well as carotenoids and phenol content in cucumber (Emmanuel et al. 2010a,b). Treatment with REE can increase SOD, CAT and POD activities of aged rice seeds (Hong et al. 2000). Similar to heavy metals, REE inhibit the enzyme activities when their concentrations exceed a critical value. For example, esterase activity increases by adding $50-100 \mu \mathrm{M}$ of REE but decreases by $200 \mu \mathrm{M}$ REE (Xin et al. 2013). Under an acid rain, REE can significantly reduce the sensitivity of antioxidant enzymes to acid stress (Yan et al. 1999).

Another effect of REE, in this case lanthanum nitrate treatment, decreases free-radical production rate and peroxidation of membrane lipids in rice seeds (Fashui and Zhenggui 2000). A monazite soil (soil containing REE) significantly increases POD and SOD activities as well as activities of amylase and nitrogenase. Increased enzyme activities in the presence of REE influence nodulation, coleoptile formation, and biomass production in Arachis hypogaea (Emmanuel et al. 2010a,b).

Biosynthesis of certain secondary metabolites supported by REE, e.g., taxol (Wu et al. 2001, Zhang et al. 2013), crocin (Chen et al. 2004), phenylethanoid glycosides (Ouyang et al. 2003), alkaloids, raubasine, and flavonoids (Evans 1983, Yuan et al. 2002, Zhang et al. 2013) has been observed in Taxus sp., Crocus sativus, Cistanche deserticola, Catharanthus roseus, Saussurea medusa, Tetrastigma hemsleyanum, and Gingko biloba. The stimulation of secondary metabolite prodution may be associated with the stimulation of specific enzymes that control their biosyntheses (Yuan et al. 2002, Ouyang et al. 2003), and these enzymes respond to very low concentrations of REE (Evans 1983, Yuan et al. 2002). If $\mathrm{Ce}^{3+}$ and $\mathrm{La}^{3+}$ are added to the medium the cell growth is stimulated as well as the amount of specific metabolites (e.g. carotenoid crocin) and their effect on plant physiology can be synergic (Chen et al. 2004).

the plant species and soil. Two indicators which might help to determinate a critical REE concentration are Chl $a / b$ ratio and leaf POD activity (Zeng et al. 2006).

Impact of Ce on lichen Xanthoria parietina was also investigated. A decreased sample viability is a consequence of $\mathrm{Ce}(0.1-100 \mathrm{mM})$ toxicity. Moreover membrane lipids peroxidation, ultrastructural changes and decreased photosynthetic performance are recorded (Paoli et al. 2014).

There are two opposing opinions concerning REE toxicity: a) REE are of limited toxicity and not considered extremely hazardous to the environment (Thomas et al. 2014); b) a slow accumulation in the environment could become a problematic issue - the 
situation in soil ecosystems is considered as becoming a serious environmental problem (Zhimang et al. 2001). The first opinion is also supported by Rühling and Tyler (2004), who demonstrated changes in the content of REE and other elements in moss carpets in south Sweden. Content of REE significantly and considerably decreased between 1975 and 2000. The median content of REE in soil was $2.5-2.8$ times higher in 1975 than in 2000. A similar result was obtained by Markert and De Li (1991). Content of REE in forest species (Betula alba, Pinus sylvestris, Vaccinium vitis-idea, Vaccinium myrtillus, Deschampsia flexuosa, Polytrichum sp.) was in relatively narrow ranges between 1987 and 1990.

Nevertheless, possible ecotoxicological effects and mechanism of action of these elements are still poorly understood (Gonzalez et al. 2014). As shown in this review, there is no clear pattern of increasing or decreasing accumulation with atomic properties (Gonzalez et al. 2014), distribution, fractionation, or hyperaccumulation in different plants. However, there is no doubt that dramatic increases in REE content in soil ecosystems has become a serious problem in some cases (Zhimang et al. 2001). Because of many applications, their global production has increased exponentially in the last decades, and their natural biogeochemical cycles are being disrupted by human uses (Gonzalez et al. 2014). The results of experiments conducted on four citrus farms in Brazil are alarming. The total content of $\mathrm{La}, \mathrm{Ce}$, and $\mathrm{Nd}$ in orange juice was 4 to 5 time higher than safety levels of REE in drinking water (Turra et al. 2013). Further, high REE concentrations are inhibiting or are even toxic to plants grown around mining facilities (Anawar et al.2012). The content of REE in mining areas might be even hundreds of times higher than in nonmining areas (Liang and Li 2014). Those REE are easily mobile and are transported among different environmental components. They enter into food chains and may have harmful effects on human (Liang et al. 2014).

Information about the toxicological effects of REE on living organisms is very limited. Available studies have dealt rather with REE mixtures than with individual elements (Pagano et al. 2015, Rim 2016). In general, toxicity was observed mainly for soluble lanthanide compounds, such as chlorides, nitrates, and sulphates, whereas insoluble forms (carbonates, phosphates, and hydroxides) are practically non-toxic.

REEs behave similarly to other xenobiotics - they show stimulatory or protective effects at low concentrations but disruptive effects in high concentrations (Pagano et al. 2015). Broad extension of REE damage effects were recorded in humans exposed to rare earth elements dust: pneumoconiosis (Xiao et al. 1997), embolism, damage of liver (Palmer et al. 1987) or itching, sensitivity to heat and skin lesion (Pairon et al. 1995). It is supposed that REE can be metabolized in human body and some of them are probably biopersistent (Pairon et al. 1995).

As shown in the studies described above, the environment is changing as well as the REE content in it. One way to monitor the status of REE in the environment over the long-term is through biomonitoring. Biomonitors can indicate REE contamination in soil and the atmosphere. Stand of Juniperus communis (Närhi et al. 2014), native plant vegetation (Durães et al. 2014), lichens (Anawar et al. 2012), carpet-forming mosses (Rühling and Tyler 2004, Tyler and Olsson 2006), and mangrove sediments (Silva-Filho et al. 2011) can serve as indicators of REE for evaluation of a possible anthropogenic impact.

\section{Conclusions}

The REE occur naturally in different ecosystems mostly depending on the rhizosphere (Fu et al. 2001). Nevertheless, near industrial and mining sites the concentration of REE can rise highly above common levels and become a part of soil and ground water. Especially some indigenous species (Asclepias syriaca, Desmodium canadense, and Panicum virgatum) - usually more sensitive than crops - can suffer from toxic REE concentration (Carpenter et al. 2015).

The effects of REE on plants can be divided into three groups: beneficial, inhibitory, and toxic (Redling 2006). However, the boundary between beneficial and inhibitory effects is very thin and depends on many factors resulting from the concentration and plant species. These factors include the origin of REE enrichment, soil, water content in soil and plants, the concentration of REE and their combination, redox potential, ability of elements to bind to compounds, and activity of soil bacteria, among others.

The most commonly described elements in the literature include $\mathrm{La}, \mathrm{Ce}, \mathrm{Pr}, \mathrm{Nd}, \mathrm{Sm}$, and $\mathrm{Eu}$, which are

widely used fertilizers ( $\mathrm{Hu}$ et al. 2004). There are many studies describing the impact of REE on crops. More than 100 crop species have been shown to respond positively to REE, with yield increases of 5 to $15 \%$ (Hu et al. 2004). The REE can affect many physiological processes in plants. The most commonly described effects include their effects on photosynthesis, Chl content, Rubisco activity, biomass production, cytoplasmic membranes, nutrient metabolism, hormone interactions, enzymes, water use efficiency, germination and growth, the amount of sugar and other metabolites, and the amount of vitamins, among others. Further, use of REE can improve plant resistance to diseases, e.g., the soft-rotten disease in cabbage (Hu et al. 2004).

There are further impacts of REE on plants than those described above, and some of the consequences are still unknown. However, it should be noted that the effect of REE on plants is comprehensive. We cannot exclude a positive effect on one species of plant and thus ignore negative consequences in a broader sense on the whole 
ecosystem. Generally, REE at low concentrations promote growth, and high doses have inhibitory effects. However, there are large differences in the impact of REE on individual plants such as the distribution of elements within the plant, absorption of REE, fractionation, and influence of individual elements on specific parts of plants. Hyperaccumulators that have the ability to accumulate larger amounts of REE with minimal negative consequences to the plant itself, e.g., Phytolacca americana, are very interesting for a possible remediation (Wu et al. 2013).

An additional research could provide missing

\section{References}

Aide, M.T., Aide, C.: Rare earth elements: their importance in understanding soil genesis. - ISRN Soil Sci. 2012: 1-11, 2012.

Anawar, H.M., Freitas. M.C., Canha, N., Dionísio, I.,Dung, H.M., Galinha, C., Pacheco,A.M.G.: Assessment of bioaccumulation of REEs by plant species in a mining area by INAA. - J. Radioanal. Nucl. Chem. 294: 377-381, 2012.

Aruguete, D.M., Aldstadt, J.H., Mueller, G.M.: Accumulation of several heavy metals and lanthanides in mushrooms (Agaricales) from the Chicago region. - Sci. total Environ. 224: 43-56, 1998.

Brioschi, L., Steinmann, M., Lucot, E., Pierret, M.C., Stille, P., Prunier, J., Badot, P.M.: Transfer of rare earth elements (REE) from natural soil to plant systems: implications for the environmental availability of anthropogenic REE. Plant Soil 366: 143-163, 2013

Cao, X., Chen, Y., Wang, X., Deng, X.: Effects of redox potential and $\mathrm{pH}$ value on the release of rare earth elements from soil. - Chemosphere 44: 655-661, 2001.

Cao X., Wang X, Zhao G.: Assessment of the bioavailability of rare earth elements in soils by chemical fractionation and multiple regression analysis. - Chemosphere 40: 23-28, 2000.

Carpenter, D., Boutin, C., Allison, J.E., Parsons, J.L., Ellis, D.M.: Uptake and effects of six rare earth elements (REEs) on selected native and crop species growing in contaminated soils. - PLoS ONE 10(6): e0129936, 2015.

Chen, S.A., Zhao, B., Wang, X., Yuan, X., Wang, Y.: Promotion of the growth of Crocus sativus cells and the production of crocin by rare earth elements. - Biotechnol. Lett. 26: 27-30, 2004.

Chen, W.J., Gu, Y.H., Zhao, G.W., Tao, Y., Luo, J.P., Hu, T.D.: Effects of rare earth ions on activity of RuBPcase in tobacco. - Plant Sci. 152: 145-151, 2000.

Chen, X.H., Zhao, B.: Arbuscular mycorrhizal fungi mediated uptake of lanthanum in Chinese milk vetch (Astragalus sinicus L.). - Chemosphere 68: 1548-1555, 2007.

Chen, X.H., Zhao, B.: Arbuscularmycorrhizal fungi mediated uptake of nutrient elements by Chinese milk vetch (Astragalus sinicus L.) grown in lanthanum spiked soil. Biol. Fertil. Soils 45: 675-678, 2009.

Dai, H., Shan, C., Zhao, H., Jia, G., Chen, D.: Lanthanum improves the cadmium tolerance of Zea mays seedlings by the regulation of ascorbate and glutathione metabolism. Biol. Plant. 61: 551-556, 2017.

De Araújo, A.L.L., De Nadai Fernandes, E.A., Bacchi, M.A., De França, E.J.: Bioaccumulation pattern of lanthanides in pteridophytes and magnoliophytes species from Atlantic information regarding the impact of REE on plant basic functions such as respiration or plant defense. The basic questions related to plant physiology were generally answered. Now the investigation should be focused on feedback of REE utilization in relation to animal and human health.It is known that REE can leach out into aquatic environments. It is absorbed by vegetation as part of the mineral nutrition and can enter the human foodchain (Chua 1998). Despite the research progress in the last few decades, certain areas of research are still missing, which could explain the inconsistent information regarding REE.
Forest. - J. Radioanal. Nucl. Chem. 291: 187-192, 2012.

Ding, S., Liang, T., Yan, J., Zhang, Z., Huang, Z., Xie, Y.: Fractionations of rare earth elements in plants and their conceptive model. - Sci. China, Ser. C Life Sci. 50: 47-55, 2007.

Ding, S., Liang, T., Zhang, C., Yan, J., Zhang, Z., Sun, Q.: Role of ligands in accumulation and fractionation of rare earth elements in plants. - Biol. Trace Element Res. 107: 73-86 2005.

Ding, S.M., Liang, T., Zhang, C.S., Wang, L.J., Sun, Q.: Accumulation and fractionation of rare earth elements in a soil-wheat system. - Pedosphere 16: 82-90, 2006.

Dobransky, S.: Rare earth elements and U.S. foreign policy: the critical ascension of REEs in global politics and U.S. national security. - In: APSA 2012 Annual Meeting. Pp. 1-45, 2013. https://ssrn.com/abstract=2106716.

Durães, N., Da Silva, E.F., Bobos, I., Ávila, P.: Rare earth elements fractionation in native vegetation from the Moncorvo iron mines, NE Portugal. - Proc. Earth Planet Sci. 10: 376-382, 2014.

El-Ramady, H.R.H.: A contribution on the bio-actions of rare earth elements in the soil/plant environment. - Thesis, Technischen Universität, Braunschweig 2008.

Emmanuel, E.S.C., Anandkumar, B., Natesan, M., Maruthamuthu, S.: Efficacy of rare earth elements on the physiological and biochemical characteristics of Zea mays L. - Aust. J. Crop Sci. 4: 289-294, 2010a.

Emmanuel, E.S.C., Ramachandran, A.M., Ravindran, A.D., Natesan, M., Maruthamuthu,S.: Effect of some rare earth elements on dry matter partitioning, nodule formation and chlorophyll content in Arachis hypogaea L. plants. - Aust. J. Crop Sci. 4: 670-675, 2010 b.

Evans, C.H.: Interesting and useful biochemical properties of lanthanides. - Trends Biochem. Sci. 8: 445-449, 1983.

França, E.J., De NadaiFernandes, E.A., Bacchi, M.A., Tagliaferro, F.S.: Pathway of rare-earth elements in a Brazilian forestry fragment. - J. Alloys Comp. 344: 21-26, 2002.

Fu, F., Akagi, T., Shinotsuka, K.: Distribution pattern of rare earth elements in fern: implication for intake of fresh silicate particles by plants. - Biol. Trace Element Res. 64: 13-26, 1998.

Fu, F., Akagi, T., Yabuki, S., Iwaki, M.: The variation of REE (rare earth elements) patterns in soil-grown plants: a new proxy for the source of rare earth elements and silicon in plants. - Plant Soil 235: 53-64, 2001.

Fu, F., Akagi, T., Yabuki, S., Iwaki, M., Ogura, N.: Distribution of rare earth elements in seaweed: Implication of two 
different sources of rare earth elements and silicon in seaweed. - J. Phycol. 70: 62-70, 2000.

Gao, Y., Zeng, F., Yi, A., Ping, S., Jing, L.: Research of the entry of rare earth elements $\mathrm{Eu}^{3+}$ and $\mathrm{La}^{3+}$ into plant cell. Biol. Trace Element Res. 91: 253-265, 2003.

Gonzalez, V., Vignati, D.A.L., Leyval, C., Giamberini, L.: Environmental fate and ecotoxicity of lanthanides: are they a uniform group beyond chemistry? - Environ. Int. 71: 148$157,2014$.

Gu, X., Wang, X., Gu, Z., Dai, L., Chen, Y.: Effects of humic acid on speciation and bioavailability to wheat of rare earth elements in soil. - Chem. Spec. Bioavailab. 13: 83-88, 2001.

Guo, W., Zhao, R., Zhao, W., Fu, R., Guo, J., Bi, N., Zhang, J.: Effects of arbuscularmycorrhizal fungi on maize (Zea mays L.) and sorghum (Sorghum bicolor L. Moench) grown in rare earth elements of mine tailings. - Appl. Soil Ecol. 72: 85-92, 2013.

Hagerberg, D., Thelin, G., Wallander, H.: The production of ectomycorrhizal mycelium in forests: relation between forest nutrient status and local mineral sources. - Plant Soil 252: 279-290, 2003.

Hatch, G.: Rare-earth terminology - a quick refresher on the basics. - In: Technol. Met. Res. 2012. http://www.techmetalsresearch.com/2012/12/rare-earthterminology-a-quick-refresher-on-the-basics/.

Hildebrandt, U., Regvar, M., Bothe, H.: Arbuscular mycorrhiza and heavy metal tolerance. - Phytochemistry 68: 139-146, 2007.

Hong, F.S., Wang, X.F., Liu, C., Su, G.X., Wu, K., Tao, Y., Wei, Z.G.: Effect of $\mathrm{Ce}^{3+}$ on spectral characteristic of D1/D2/Cytb559 complex from spinach. - Sci. China Ser. B 46: 42-50, 2003.

Hong, F.S, Wei, Z.G., Zhao, G.W.: Effect of lanthanum on aged seed germination of rice. - Biol. Trace Elem. Res. 75: 205213, 2000.

Hong, F.S., Liu, C., Zheng, L., Wang, X.F., Wu, K., Song, W.P., Lv, S.P., Tao, Y., Zhao, G.W.: Formation of complexes of Rubisco-Rubisco activase from $\mathrm{La}^{3+}, \mathrm{Ce}^{3+}$ treatment spinach. - Sci. China Ser. B Chem. 48: 67-74, 2005.

Hong, F.S, Wei, Z.G., Zhao, G.W.: Mechanism of lanthanum effect on chlorophyll of spinach. - Sci. China C Life Sci. 45: 166-76, 2002.

Hu, Z., Richter, H., Sparovek, G., Schnug, E.: Physiological and biochemical effects of rare earth elements on plants and their agricultural significance: a review. - J. Plant Nutr. 27: 183-220, 2004

Jaireth, S., Hoatson, D.M., Miezitis, Y.: Geological setting and resources of the major rare-earth-element deposits in Australia. - Ore Geol. Rev. 62: 72-128, 2014.

Johannesson, K.H., Lyons W.B.: Rare-earth element geochemistry of Colour Lake, an acidic freshwater lake on Axel Heiberg Island, Northwest Territories, Canada. Chem. Geol. 119: 209-223, 1995.

Johannesson, K.H., Stetzenbach, K.J., Hodge, V.F., Lyons, W.B.: Rare earth element complexation behavior in circumneutral $\mathrm{pH}$ ground waters: assessing the role of carbonate and phosphate ions. - Earth Planet Sci. Lett. 139: 305-319, 1996.

Jones, D.L.: Trivalent metal (Cr, Y, Rh, La, Pr, Gd) sorption in two acid soils and its consequences for bioremediation. Eur. J. Soil Sci. 48: 697-702, 1997.

Khan, A.M., Yusoff, I., Abu Bakar, N.K., Abu Bakar, A.F., Alias, Y., Mispan, M.S.: Accumulation, uptake and bioavailability of rare earth elements (REEs) in soil grown plants from ex-mining area in Perak, Malaysia. - Appl. Ecol. Environ. Res. 15: 117-133, 2017.

Lai, Y., Wang, Q., Yang, L., Huang, B.: Subcellular distribution of rare earth elements and characterization of their binding species in a newly discovered hyperaccumulator Pronephrium simplex. - Talanta70: 26-31, 2006.

Lehmann, H., Stelzer, R., Holzamer, S., Kunz, U., Gierth, M.: Analytical electron microscopical investigations on the apoplastic pathways of lanthanum transport in barley roots. - Planta 211: 816-22, 2000.

Li, F., Shan, X., Zhang, T., Zhang, S.: Evaluation of plant availability of rare earth elements in soils by chemical fractionation and multiple regression analysis. - Environ. Pollut. 102: 269-277, 1998.

Liang, T., Ding, S., Song, W., Chong, Z., Zhang, C., Li, H.: A review of fractionations of rare earth elements in plants. - J. Rare Earths 26: 7-15, 2008.

Liang, T., Li, K., Wang, L.: State of rare earth elements in different environmental components in mining areas of China. - Environ. Monit. Assess. 186: 1499-1513, 2014.

Liang, T., Zhang, S., Wang, L., Kung, H.-T., Wang, Y., Hu, A., Ding, S.: Environmental biogeochemical behaviors of rare earth elements in soil-plant systems. - Environ. Geochem. Health 27: 301-311, 2005.

Liu, X., Su, M., Liu, C., Zhang, Y., Si, W., Hong F.: Effect of 4f electron characteristics and alternation valence of rare earths on photosynthesis: regulating distribution of energy and activities of spinach chloroplast. - J. Rare Earths 25: 495-501, 2007.

Liu, X.Q., Su, M.Y., Liu, C., Zhang, L., Si, W.H., Hong, F.H.: Effects of $\mathrm{CeCl}_{3}$ on Energy Transfer and Oxygen Evolution in Spinach Photosystem II. - J. Rare Earths 25: 624-630, 2007.

Loell, M., Albrecht, C., Felix-Henningsen, P.: Rare earth elements and relation between their potential bioavailability and soil properties, Nidda catchment (Central Germany). Plant Soil 349: 303-317, 2011.

Long, K.R., Van Gosen, B.S., Foley, N.K., Cordier, D.: The Principal Rare Earth Elements Deposits of the United States - A Summary of Domestic Deposits and a Global Perspective. - Scientific Investigations Report 2010-5220, 2010. http://pubs.usgs.gov/sir/2010/5220/.

Ma, L., Liu, C., Qu, C., Yin, S., Liu, J., Gao, F., Hong, F.: Rubisco activase mRNA expression in spinach modulation by nanoanatase treatment. - Biol. Trace Element Res. 122: 168-178, 2008.

Maksimović, I., Kastori, R., Putnik-Delić, M., Borišev, M.: Effect of yttrium on photosynthesis and water relations in young maize plants. - J. Rare Earths 32: 371-378, 2014.

Markert, B., De Li, Z.: Natural background concentrations of rare-earth elements in a forest ecosystem. - Sci. Total Environ. 103: 27-35, 1991.

Masuda, A., Kawakami, O., Dohmoto, Y., Takenaka, T.: Lanthanide tetrad effects in nature: two mutually opposite types, W and M. - Geochem. J. 21: 119-124, 1987.

Merten, D., Kothe, E., Büchel, G.: Studies on microbial heavy metal retention from uranium mine drainage water with special emphasis on rare earth elements. - Mine Water Environ. 23: 34-43, 2004.

Miao, L., Ma, Y., Xu, R., Yan, W.: Environmental biogeochemical characteristics of rare earth elements in soil and soil-grown plants of the Hetai goldfield, Guangdong Province, China. - Environ. Earth Sci. 63: 501-511, 2011.

Miao, L., Xu, R., Ma, Y., Zhu, Z., Wang, J., Cai, R., Chen,Y.: Geochemistry and biogeochemistry of rare earth elements in 
a surface environment (soil and plant) in South China. Environ. Geol. 56: 225-235, 2008.

Mikołajczak, P., Borowiak, K., Niedzielski. P.: Phytoextraction of rare earth elements in herbaceous plant species growing close to roads. - Environ. Sci. Pollut. Res. 24: 14091-14103, 2017.

Närhi, P., Middleton, M., Sutinen, R.: Biogeochemical multielement signatures in common juniper at Mäkärärova, Finnish Lapland: implications for $\mathrm{Au}$ and REE exploration. - J. geochem.Explor. 138: 50-58, 2014.

Nazreen, M. N.M., Amalina, A.N., Omar, M.N.: Bioaccumulation of rare earth element by water lettuce (Pistia stratiotes). - Orient. J. Chem. 33: 1097-1102, 2017.

Ouyang, J., Wang, X., Zhao, B., Yuan, X., Wang, Y.: Effects of rare earth elements on the growth of Cistanche deserticola cells and the production of phenylethanoid glycosides. - J. Biotechnol. 102: 129-134, 2003.

Ozaki, T., Enomoto, S., Minai, Y., Ambe, S., Ambe, F., Makide,Y.: Beneficial effect of rare earth elements on the growth of Dryopteris erythrosora. - J. Plant Physiol. 156: 330-334, 2000.

Pagano, G., Guida, M., Tommasi, F., Oral, R.: Health effects and toxicity mechanisms of rare earth elements- knowledge gaps and research prospects. - Ecotoxicol. Environ. Safety 115: 40-48, 2015.

Paoli L, Fiorini E, Munzi S, Sorbo, S, Basile, A, Loppi, S.:Uptake and acute toxicity of cerium in the lichen Xanthoriaparietina. - Ecotoxicol. Environ. Safety 104: 379385, 2014.

Peresedov, V.F., Gundorina, S.F., Ostrovnaya, T.M.: Rare-earth elements in soil and pine needle from northern terrestrial ecosystems. - J. Radioanal. Nucl. Chem. 219: 105-110, 1997

Redling, K.: Rare earth elements in agriculture with emphasis on animal husbandry. - Thesis. Ludwig-MaximiliansUniversität, München 2006.

Rim, K.T.: Effects of rare earth elements on the environment and human health: a literature review. - Toxicol. Environ. Health Sci. 8: 189-200, 2016.

Rim, K.T.: Trends in occupational toxicology of rare earth elements. - In: Pagano, G. (ed.): Rare Earth Elements in Human and Environmental Health: at the Crossroads between Toxicity and Safety. Pp. 11-46. Pan Stanford Publishing, Singapore 2017.

Rühling, A., Tyler, G.: Changes in the atmospheric deposition of minor and rare elements between 1975 and 2000 in south Sweden, as measured by moss analysis. - Environ. Pollut. 131: 417-23, 2004.

Shan, X.Q., Lian, J., Wen, B.: Effect of organic acids on adsorption and desorption of rare earth elements. Chemosphere 47: 701-710, 2002.

Shan, X.Q., Wang, H., Zhang, S., Zhou, H., Zheng, Y., Yu, H., Wen, B.: Accumulation and uptake of light rare earth elements in a hyperaccumulator Dicropteris dichotoma. Plant Sci. 165: 1343-1353, 2003a.

Shan, X.Q., Wang, Z., Wang, W., Zhang, S., Wen, B.: Labile rhizosphere soil solution fraction for prediction of bioavailability of heavy metals and rare earth elements to plants. - Anal. Bioanal. Chem. 375: 400-7, 2003b.

Silva-Filho, E.V., Sanders, C.J., Bernat, M., Figueiredo, A.M.G., Sella, S.M., Wasserman,J.: Origin of rare earth element anomalies in mangrove sediments, Sepetiba Bay, SE Brazil: used as geochemical tracers of sediment sources. - Environ. Earth Sci. 64: 1257-1267, 2011.

Sneller, F.E.C., Kalf, D.F., Weltje, L., Van Wezel, A.P.:
Maximum permissible concentrations and negligible concentrations for rare earth elements (REEs). - RIVM report $601501011,2000$.

Stille, P., Pierret, M.C., Steinmann, M.,Chabaux, F., Boutin, R., Aubert, D., Pourcelot, L., Morvan, G.: Impact of atmospheric deposition, biogeochemical cycling and watermineral interaction on REE fractionation in acidic surface soils and soil water (the Strengbach case). - Chem. Geol. 264: 173-186, 2009.

Sun, J., Zhao, H., Wang, Y.: Study on the contents of trace rare earth elements and their distribution in wheat and rice samples by RNAA. - J. Radioanal. Nucl. Chem. 179: 377 383, 1994.

Thomas, P.J., Carpenter, D., Boutin, C., Allison, J.E.: Rare earth elements (REEs): effects on germination and growth of selected crop and native plant species. - Chemosphere 96: 57-66, 2014.

Turra, C., De Nadai Fernandes, E.A., Bacchi, M.A., Sarriés, G.A., Júnior., F.B., Reyes, A.E.L.: Rare earth elements in citrus production systems. - J. Plant Nutr. 36: 762-771, 2013.

Tyler, G.: Rare earth elements in soil and plant systems - a review. - Plant Soil 267: 191-206, 2004a.

Tyler, G.: Ionic charge, radius, and potential control root/soil concentration ratios of fifty cationic elements in the organic horizon of a beech (Fagus sylvatica) forest podzol. - Sci. total Environ. 329: 231-239, 2004b.

Tyler, G., Olsson, T.: Rare earth elements in forest-floor herbs as related to soil conditions and mineral nutrition. - Biol. Trace Element Res. 106: 177-191, 2005.

Tyler, G., Olsson, T.: The importance of atmospheric deposition, charge and atomic mass to the dynamics of minor and rare elements in developing, ageing, and wilted leaves of beech (Fagus sylvatica L.). - Chemosphere 65: 250-260, 2006.

Wahid, P.A., Kamalam, N.V., Krishna Prabhu, R., Sekhar, J.K., Vijayalakshmi, S., Mahalingam, T.R., Ajith Kumar, C.E.: Rare earth element fluxes in diverse soils and their absorption by coconut Palm. - J. Plant Nutr. 26: 1427-1438, 2003.

Walters, A., Lusty, P.: Rare earth elements-commodity profile. - British geol. Survey 2011: 1-54, 2011.

Wang, L.F., Ji, H.B., Bai, K.Z.,Li, L.B., Kuang, T.Y.: Photosystem 2 activities of hyper-accumulator Dicranopteri sdichotoma Bernh from a light rare earth elements mine. Photosynthetica 44: 202-207, 2006.

Wang, X.P., Shan, X.Q., Zhang, S.Z., Wen, B.: Distribution of rare earth elements among chloroplast components of hyperaccumulator Dicranopteris dichotoma. - Anal. bioanal. Chem. 376: 913-917, 2003.

Weltje, L., Heidenreich, H., Zhu, W., Wolterbeek, H.T., Korhammer, S., De Goeij, J.J., Markert, B.: Lanthanide concentrations in freshwater plants and molluscs, related to those in surface water, pore water and sediment. A case study in The Netherlands. - Sci. total Environ. 286: 191214, 2002.

Wen, B., Yuan, D.A., Shan, X.Q., Li, F.L., Zhang, S.Z.: The influence of rare earth element fertilizer application on the distribution and bioaccumulation of rare earth elements in plants under field conditions. - Chem. Speciat. Bioavailab. 13: 39-48, 2001.

Wu, J., Chen, A., Peng, S., Wei, Z., Liu, G.: Identification and application of amino acids as chelators in phytoremediation of rare earth elements lanthanum and yttrium. - Plant Soil 373: 329-338, 2013. 
Wu, J., Wang, C., Mei, X.: Stimulation of taxol production and excretion in Taxusspp cell cultures by rare earth chemical lanthanum. - J. Biotechnol. 85: 67-73, 2001.

Wu, Z.H., Wang, X.R., Zhang, Y.F., Dai, L.M., Chen, Y.J.: Effects of apatite and calcium oxyphosphate on speciation and bioavailability of exogenous rare earth elements in the soil-plant system. - Chem. Speciat. Bioavailab. 13: 49-56, 2001.

Wyttenbach, A., Furrer, V., Schleppi, P., Tobler, L.: Rare earth elements in soil and in soil-grown plants. - Plant Soil 199: 267-273, 1998.

Wyttenbach, A., Schleppi, P., Bucher, J., Furrer, V., Tobler,L.: The accumulation of the rare earth elements and of scandium in successive needle age classes of Norway spruce. - Biol. Trace Element Res. 41: 13-29, 1994.

Xin, P., Shuang-Lin, Z., Jun-Yao, H., Li, D.: Influence of rare earth elements on metabolism and related enzyme activity and isozyme expression in Tetrastigma hemsleyanum cell suspension cultures. - Biol. Trace Element. Res. 152: 82-90, 2013.

$\mathrm{Xu}, \mathrm{X}$., Wang, Z.: Effects of lanthanum and mixtures of rare earths on ammonium oxidation and mineralization of nitrogen in soil. - Eur. J. Soil Sci. 52: 323-329, 2001.

$\mathrm{Xu}, \mathrm{X}$., Wang, Z.: Phosphorus uptake and translocation in fieldgrown maize after application of rare earth-containing fertilizer. - J. Plant Nutr. 30: 557-568, 2007.

Yan, C., Hong, Y., Yang, X., Fu, S., Wu, S.: Biological effect of rare-earth elements on anti-oxidation enzymes in wheat under acid rain stress. - Chinese Sci. Bull. 44: 1-4, 1999.

Yang, F., Ma, Z.N., Liu, C., Wu, C., Zhou, J., Gao, F.Q., Hong,
F.S.: Effects of $\mathrm{Ce}^{3+}$ on chloroplast senescence of spinach under light. - J. Rare Earths 23: 480-485, 2005.

Yuan, X.F, Wang, Q., Zhao, B., Wang, Y.C.: Improved cell growth and total flavonoids of Saussurea medusa on solid culture medium supplemented with rare earth elements. Biotechnol. Lett. 24: 1889-1892, 2002.

Zanin, Y.N., Zamirailova, A.G.: Rare earth elements in supergene phosphorites. - Geochemistry Int. 47: 282-296, 2009.

Zeng, F.L., Shi, P., Zhang, M.F., Deng, R.W.: Effect of lanthanum on ion absorption in cucumber seedling leaves. Biol. Trace Element. Res. 78: 265-270, 2000.

Zeng, Q., Zhu, J.G., Cheng, H.L., Xie, Z.B., Chu, H.Y.: Phytotoxicity of lanthanum in rice in haplicacrisols and cambisols. - Ecotoxicol. Environ. Safety 64: 226-233, 2006.

Zhang, C., Li, Q., Zhang, M., Zhang, N., Li, M.: Effects of rare earth elements on growth and metabolism of medicinal plants. - Acta pharm. sin. B 3: 20-24, 2013.

Zhang, S., Shan, X.Q.: Speciation of rare earth elements in soil and accumulation by wheat with rare earth fertilizer application. - Environ. Pollut. 112: 395-405, 2001.

Zhimang, G., Xiaorong, W., Xueyuan, G., Jing, C., Liansheng W., Lemei, D., Yijun, C.: Effects of fulvic acid on the bioavailability of rare earth elements and GOT enzyme activity in wheat (Triticum aestivum). - Chemosphere 44: 545-551, 2001.

Zhou, M., Ze,Y., Li, N., Duan, Y., Chen, T., Liu, C., Hong, F.: Cerium relieving the inhibition of photosynthesis and growth of spinach caused by lead. - J. Rare Earths 27: 864869, 2009. 